\title{
Surveying the effects of an exercise program on the sleep quality of elderly males
}

\author{
This article was published in the following Dove Press journal: \\ Clinical Interventions in Aging \\ 27 July 2016 \\ Number of times this article has been viewed
}

\author{
Saba Karimi' \\ Ali Soroush ${ }^{2}$ \\ Farhad Towhidi ${ }^{3}$ \\ Behnam Reza Makhsosi ${ }^{3}$ \\ Maryam Karimi ${ }^{4}$ \\ Saeid Jamehshorani ${ }^{3}$ \\ Afshin Akhgar ${ }^{3}$ \\ Mahmoud Fakhri ${ }^{4}$ \\ Alireza Abdi ${ }^{5}$ \\ 'Internal and Surgical Department, \\ School of Nursing and Midwifery, \\ ${ }^{2}$ Lifestyle Modification Research \\ Department, ${ }^{3}$ Exercise Physiology, \\ Imam Reza Hospital, Kermanshah \\ University of Medical Sciences, \\ ${ }^{4}$ Paramedical Science, Kermanshah \\ University of Medical Sciences, \\ Kermanshah, ${ }^{5}$ Internal and Surgical \\ Nursing Department, Nursing and \\ Midwifery School, Shahid Beheshti \\ University of Medical Science, \\ Tehran, Iran
}

Background: Old age is a stage of life featured with many physiological and mental changes. The Iranian population is aging, and one of the problems that the elderly are faced with is sleep disorders. The present study is an attempt to examine the effectiveness of an exercise program on the sleep quality of the elderly.

Methods: A semi-experimental study was carried out on the elderly males referred to the Shahid Yari Elderly Center, Kermanshah, Iran. The sample group comprised of 46 participants: 23 in the experimental group and 23 in the control group. The study was carried out for a period of 2 months and follow-up was conducted every week. To improve the quality of sleep of the participants, a four-stage exercise program was implemented and the collected data were analyzed by SPSS version 20 .

Results: The results of a Mann-Whitney test showed that the quality of sleep of the majority in the experimental group improved compared with that of the control group $(P<0.05)$. In addition, a Wilcoxon test showed improvement of the Petersburg's sleep quality index based on subelements and the results of a total score of sleep in the experimental group after the intervention. Conclusion: The study showed effectiveness of scheduled exercising on the quality of sleep of the elderly. It is recommended, therefore, to add an exercise program to the daily program of the elderly.

Keywords: aged, sleep, exercises

\section{Introduction}

Old age is a natural biological and inevitable phenomenon of a human's life, which is the result of gradual degradation of vital organs. ${ }^{1}$ The current trend of the aging population has convinced the French gerontology association that the population of the society is shifting from children population explosion to the elderly population explosion. ${ }^{2,3}$ According to the United Nations reports, the world elderly population ( $>60$ years) in 2006 was more than 687 million and this figure will reach two billion by 2050 . The United Nations forecasts for the time frame 2025-2030 indicate that the 60-year and older population will experience a growth rate 3.5 times more than that of the general population $(2.8$ compared to 0.80 ). Iranian population follows the same trend and the forecasts say that the country will face an elderly population explosion by 2031 (25\%-30\% above 50 years) and the elderly population will reach 26 million by $2049.4^{4-7}$

Due to an increased life expectancy, less active lifestyle, and technology, a variety of physical, mental, social, and economic problems have arisen. ${ }^{8,9}$ Some of the studies have indicated that aging is due to malfunction of different biological systems, mostly due to motor limitations, and leads to one's dependence on others in doing daily activities. These factors may influence one's sense of goodness and quality of life. Adopting an active lifestyle featured with physical activities and doing exercise have
Correspondence: Ali Soroush Lifestyle Modification Research Department, Kermanshah University of Medical Sciences, Parastar Bolvar, Sorkhalizhe street, Post Box 67I893488I, Kermanshah, Iran

Tel +988319188309157

Fax +98 8318334282668

Email ali.soroush.mhr@gmail.com
Clinical Interventions in Aging 2016:11 997-1002

997 
been proved effective in the improvement of the elderly's quality of life. ${ }^{10}$

Routine physical activities reduce the injuries sustained by stumbling or falling down, improve the elderly's physical balance and coordination, and increase muscular strength. Lack of physical activity in the elderly increases the risk of osteoporosis, obesity, depression, and unexpected death due to cardiovascular diseases, diabetes type 2, colon cancer, and sleep disorders. ${ }^{11}$ One of the main effects of physical activities in all ages and old ages, in particular, is on the quality of sleep as it is one of the main factors in the elderly's life. Aging induces changes in quality and structure of sleep. This is identified by change of timing and regularity of bed time, commencing of sleep, awakening at night, napping during the day, and decrease in rapid eye movement period. ${ }^{12}$ There are many controversies over the causes of sleep disorders in the elderly: some attributed this to the change in circadian clock and rhythm, ${ }^{12,13}$ and others declared the variation in melatonin rhythm is the main reason for this perturbation. ${ }^{14}$ However, for whatever reason, the changes that lead to sleep disorders can result in poor quality of sleep in the elderly, and consequently poor health, decrease of physical performance, increase of death risk, decrease of quality of life, higher risk of mental diseases, decrease in physical performance over the day, emotions and thoughts disorders, loss of motivation, decrease in immune system activity, reduced hypothalamus, adrenal and pituitary functioning, causing glucose tolerance and as a result, diabetes and hypertension, as well as an increase in the risk of cardiovascular events. ${ }^{6,15}$ To fight the sleep disorders, people tend to use sleep medications, which induce physical and mental side effects. Although medicinefree treatment methods are more stable and featured with fewer side effects, they need more time to induce their effects compared with sleep medications. Doing physical activities is one of the ways to pacify the elderly, as they induce growth hormone secretion, reserve energy of the body, and increase general health of the body. Therefore, physical activity is suggested as a solution to improve initiation and trend of sleep. ${ }^{11}$ The benefits of exercise and physical activity could be ascribed to energy conservation, body restoration, and thermoregulatory functions. ${ }^{16}$ Previous studies have verified the effect of exercise on the quality of sleep in the elderly: these effects varied according to the intensity and duration of the workout; ${ }^{17}$ accordingly, in Santos et al, ${ }^{18}$ a moderate exercise done by 22 old males for 24 weeks improved some sleep parameters, such as rapid eye movement latency and time awake and these results were attributed to the antiinflammatory effect of moderate training. In another study conducted by Durcan et al, ${ }^{19}$ the exercise reduced the rate of fatigue, pain, and sleep disorder in patients. Yang et $\mathrm{al}^{20}$ in a review study indicated that exercise can even rectify the sleep latency, but no change was observed for other sleep indices, such as sleep duration, sleep efficiency, sleep disturbance, and daytime functioning. Another meta-analysis performed by Kredlow et $a^{21}$ on the effect of exercise on sleep quality, including 66 current studies, showed there are many different beneficial effects of the physical exercise programs in terms of intensity, duration, exercise type, sex, and age that had demanded other studies in this field.

Due to the lack of a good and satisfying sleep in elderly people, which causes chronic tiredness and frustration; they contribute these sleep disorders to the high age, as a result, do not seek the required treatments. ${ }^{22}$ Thus, detecting the factors that influence the quality of sleep in the elderly is of prominent importance. ${ }^{23}$ Although the exercise program has been recommended to reduce the sleep disturbance in the elderly, considering the few and controversial studies in the field and knowing that sleep is a vital need for the human body, ${ }^{20,21}$ the present study is aimed to examine the effect of an exercise program on the quality of sleep of the elderly people.

\section{Methods}

The research was approved by the ethics committee of the research deputy affiliated to Kermanshah University of Medical Sciences. The study was carried out as a clinical trial in the Kermanshah Shahid Yari Elderly House. The study population was comprised of all the elderly referred to this center and the sample size estimated by confidence coefficient $=95 \%$, power of $80 \%$ and regarding to mean and standard deviation of similar studies, ${ }^{11,23}$ and statistical formula stated by Rohrig et al, ${ }^{24} 16$ individuals were estimated for each group size, however, due to likelihood of attrition 23 participants (overall 46) were selected. It is notable that in a review study by Yang et al, ${ }^{20}$ the number of participants was maintained from 17 to 60 individuals. After briefing the participants and obtaining written informed consent for participation, 46 individuals who met the inclusion criteria were selected based on random figure table. Afterwards, the participants were equally distributed to the experiment and control groups using random blocks method.

Inclusion criteria included age $>60$ years, primary insomnia based on diagnosis records, desire to participate, literacy levels (reading and writing), smoking less than ten cigarettes per day, and a Petersburg's index score $<5$. Being diagnosed with secondary insomnia due to medical problems 
and reluctance to participate in the study were exclusion criteria. To collect the data, Petersburg's sleep quality index designed by Buysse et $\mathrm{al}^{25}$ in 1989 was used to measure the quality of sleep and diagnose people suffering from poor sleep. This tool was used by other studies to determine the quality of sleep in old people during the 1-month period. . $^{19,22,26}$ The questionnaire was validated to assess the sleep disorders among the elderly by some researchers in Iran. ${ }^{22,27,28}$ In our study, to examine the validity of the questionnaire, content validity was used. The reliability was estimated by calculating Cronbach's alpha equal to $91 \%$ over ten completed questionnaires in a pilot study.

The tool has nine items, four of them are about sleeping and awaking times which were designed as the short-response questions. Accordingly, for more than 7 hours sleep the score 0, 6-7 score 1, 5-6 score 2, and less than 5 hours score 3 were allotted. Item 5 had ten subitem questions that accompany other items (5-9) with a score of 4 points in Likert (0-3). The tool covers seven different fields, including quality of mental sleep (item 9: during the past month, overall, how was the quality of your asleep?), delay in falling asleep (item 2 and 5A, such as: during the past month, how much minutes passed before falling asleep), term of sleep (items 4: during the past month, how long have you had quality sleep?), adequacy of sleep habits (items 1, 3, and 4, such as: during the past month, when did you wake up in the morning), sleep disorders (items 5B-5D, such as: during the past month, did you wake up in midnight or early in the morning?), taking sleep drugs (item 6: during the past month, how many times did you use sedative medications for sleeping?), and disorders in physical performance over the day (items 7 and 8, such as: during the past month, how many times did you have problems driving, eating, or working?). The tool is easy to understand and implement and the answers are scored from 0 to 3; maximum and minimum scores are 21 and 0 , respectively. The designer believes scores above 5 indicate considerable sleep problem.

Data were gathered in 2014 for a period of 2 months; for this purpose, after receiving permission from vice-chancellor of Kermanshah University of Medical Sciences, the researcher referred to the Shahid Yari Elderly House, and then the aim of the study was explained to the participants. They were assured about confidentiality and anonymity of personal information, and written informed consent was obtained. First, the demographic information of the participants was collected before the intervention; then, the participants were asked to fill out Petersburg's questionnaire before and after the intervention. The experiment group was given an activity program of 30 minutes walking three times a week. Before implementing the program, the author monitored the physical strength and vital signs and changed the physical activity program if needed. The participants with abnormal vital signs were excluded from the physical activity program. Moreover, to check the intensity of the movements, the vital signs were monitored during the exercises. Hence, for those who had abnormal symptoms, necessary care had been taken. The exercise program included warming up and preparation stages (5 minutes), walking as fast as possible (10 minutes), slow walking to cool down (5 minutes), and resting and relaxation (10 minutes). The 5-minute warming up was featured with slow walking and warm up in motion followed by a main walking program for 10 minutes, and cooling down for 5 minutes (slow walking). The participants would lie down for 10 minutes and take deep breaths and close their eyes. The exercise program was followed for 8 weeks and the participants were under direct observation of the researcher. It is notable that the exercise program was performed under the supervision of a chief nurse and sports medicine specialist.

The data were analyzed using mean, standard deviation, chi-square test for qualitative data, and Wilcoxon and MannWhitney tests for quantitative data by SPSS20 software.

\section{Results}

In this study, 46 people participated - all of them were male. They were divided into two groups (experiment and control). The mean of age of the experiment and control groups was 67.49 and 66.82 years, respectively, and the majority of the participants (36.95\%) had a high school diploma. However, 50\% of the participants did not have enough income. Demographic information of the participants is listed in Table 1;

Table I Demographic information

\begin{tabular}{|c|c|c|c|}
\hline Education & $\begin{array}{l}\text { Experiment } \\
\mathbf{N}=\mathbf{2 3}\end{array}$ & $\begin{array}{l}\text { Control } \\
N=23\end{array}$ & $\begin{array}{l}\text { Statistical } \\
\text { tests }\end{array}$ \\
\hline Barely literate & $3(13)$ & $4(17.4)$ & $\chi^{2}=95.2$ \\
\hline Elementary school & $2(8.77)$ & $3(13)$ & $d f=6$ \\
\hline Preliminary high school & I (4.3) & $3(13)$ & $P=0.88$ \\
\hline High school diploma & $9(39.1)$ & $8(34.8)$ & \\
\hline Associates' degree & $5(21.7)$ & $2(8.7)$ & \\
\hline Bachelors' degree & $3(13)$ & $3(13)$ & \\
\hline \multirow[t]{2}{*}{ Income } & Experiment & Control & \\
\hline & $\mathbf{N}=\mathbf{2 3}$ & $\mathbf{N}=\mathbf{2 3}$ & \\
\hline Adequate revenue & II (4I.8) & II (47.8) & $\chi^{2}=3.20$ \\
\hline Revenue more than & $0(0)$ & I (4.3) & $d f=2$ \\
\hline needed & & & $P=0.65$ \\
\hline Inadequate revenue & $12(52.2)$ & II (47.8) & \\
\hline Age (years), mean $\pm S D$ & $67.49 \pm 4.28$ & $66.82 \pm 3.84$ & $P=0.56$ \\
\hline
\end{tabular}

Note: Data presented as $\mathrm{n}(\%)$ unless stated otherwise.

Abbreviations: $d f$, degrees of freedom; SD, standard deviation. 
Table 2 Mean score of the elements of Petersburg Sleep Quality Index before and after intervention

\begin{tabular}{|c|c|c|c|c|c|c|c|}
\hline \multirow[t]{2}{*}{ Sleep indexes } & \multicolumn{3}{|l|}{ Experiment } & \multicolumn{3}{|l|}{ Control } & \multirow[t]{2}{*}{ Mann-Whitney } \\
\hline & $\begin{array}{l}\text { Mean (SD) } \\
\text { pretest }\end{array}$ & $\begin{array}{l}\text { Mean (SD) } \\
\text { posttest }\end{array}$ & $\begin{array}{l}\text { Wilcoxon } \\
\text { P-value }\end{array}$ & $\begin{array}{l}\text { Mean (SD) } \\
\text { posttest }\end{array}$ & $\begin{array}{l}\text { Mean (SD) } \\
\text { pretest }\end{array}$ & $\begin{array}{l}\text { Wilcoxon } \\
\text { P-value }\end{array}$ & \\
\hline $\begin{array}{l}\text { Quality of } \\
\text { mental sleep }\end{array}$ & I (0.67) & $0.60(0.58)$ & 0.01 & $0.91(0.5 I)$ & $0.73(0.54)$ & 0.10 & $\begin{array}{l}P \text { pretest }=0.78 \\
P \text { posttest }=0.03 \\
z=-2.28\end{array}$ \\
\hline $\begin{array}{l}\text { Delay in going } \\
\text { to sleep }\end{array}$ & $1.39(1.07)$ & $0.47(0.89)$ & 0.001 & $0.95(1.06)$ & $0.96(1.06)$ & 0.10 & $\begin{array}{l}P \text { pretest }=0.16 \\
P \text { posttest }=0.001 \\
z=-3.01\end{array}$ \\
\hline Term of sleep & $1.52(1.03)$ & $0.78(0.90)$ & 0.004 & $0.82(0.98)$ & $0.91(0.99)$ & 0.71 & $\begin{array}{l}P \text { pretest }=0.85 \\
P \text { posttest }=0.006 \\
z=-2.36\end{array}$ \\
\hline Quality of sleep & $1.04(1.33)$ & $0.60(0.98)$ & 0.09 & $0.56(1.03)$ & $0.49(0.78)$ & 0.49 & $\begin{array}{l}P \text { pretest }=0.56 \\
P \text { posttest }=0.001 \\
\mathrm{z}=-2.24\end{array}$ \\
\hline Sleep disruption & I. $17(0.38)$ & $0.78(0.5 \mathrm{I})$ & 0.007 & $1.04(0.20)$ & $0.97(0.4 \mathrm{I})$ & 0.18 & $\begin{array}{l}P \text { pretest }=0.36 \\
P \text { posttest }=0.009 \\
z=-2.96\end{array}$ \\
\hline $\begin{array}{l}\text { Using sleep } \\
\text { medicine }\end{array}$ & $1.13(1.42)$ & $0.73(1.28)$ & 0.09 & $1.08(1.45)$ & $1.18(1.28)$ & 0.73 & $\begin{array}{l}P \text { pretest }=0.77 \\
P \text { posttest }=0.043 \\
z=-2.39\end{array}$ \\
\hline $\begin{array}{l}\text { Problems in } \\
\text { doing daily tasks }\end{array}$ & $0.34(0.48)$ & $0.13(0.34)$ & 0.02 & $0.30(0.63)$ & $0.26(0.54)$ & 0.14 & $\begin{array}{l}P \text { pretest }=0.28 \\
P \text { posttest }=0.01 \\
z=-2.32\end{array}$ \\
\hline Total score & $7.59(0.68)$ & 4.09 (3.57) & 0.001 & $5.66(3.08)$ & $5.5(0.5 \mathrm{I})$ & 0.14 & $\begin{array}{l}P \text { pretest }=0.91 \\
P \text { posttest }=0.004 \\
z=-4.87\end{array}$ \\
\hline
\end{tabular}

Abbreviation: SD, standard deviation.

clearly, there was no significant difference between the average age of the participants in the control and experiment groups ( $P=0.56)$. In addition, the participants in the two group were almost identical regarding education level $(P=0.88)$. With regard to income, there was no significant difference between the two groups $(P=0.65)$.

Results listed in Table 2 indicate the mean and standard deviation of sleep quality in experiment and control groups equal to $7.59 \pm 0.68$ and $5.66 \pm 3.08$ respectively, before intervention. The sleep quality of the experiment group was significantly reduced to $4.09 \pm 3.57$ ( $P=0.001$ ), which indicates an improvement in the quality of sleep. This decrease happened in all the dimensions of sleep quality other than "using sleep medicine". In the case of the control group, the scores show a little increase at posttest stage compared with

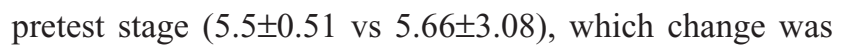
not significant $(P=0.14)$. Moreover, the Mann-Whitney test result indicates that there is a significant difference between the two groups at posttest stage in terms of the elements of quality of sleep, delay in falling into sleep, term of sleep, using sleep medicine, problems in doing daily tasks, and also the general quality of sleep $(P=0.004)$. Therefore, the exercise program was effective in improving the quality of sleep of the participants.

\section{Discussion}

In this study, the effects of the exercise program on quality of sleep of male elderly were examined. The results showed that there was a significant difference between the two groups at posttest stage regarding the elements of quality of sleep, delay in falling into sleep, term of sleep, using sleep medicines, problems in doing daily tasks, and general quality of sleep. Therefore, the exercise program resulted in an increase in quality of sleep of the elderly along with the increase in quality of mental sleep, a reduction in the time needed to fall asleep, an increase in the term of sleep, a decrease in the need for sleep drugs, and a decrease in problems in doing daily tasks. Our results are consistent with Ferris et al, ${ }^{29}$ King et al, ${ }^{30}$ Elavsky et al, ${ }^{31}$ and $\mathrm{Li}$ et $\mathrm{al}^{26}$ that supported the effectiveness of physical activity on quality of sleep. In addition, Rahmaninia et $\mathrm{al}^{32}$ reported that a walking program of 8 weeks was effective in improving the quality of sleep of the elderly.

To explain the findings, according to the theory of preserving the energy of the body, physical activity can 
induce positive changes in circadian rhythms and increase adenosine levels in the body. These changes have a positive effect in regulating sleep and preserving energy of the body. On the other hand, physical activities induce hormone secretion and considerably improve quality and quantity of sleep. Adequate secretion of growth hormone during sleep helps in reserving the resources of the body and prevents decrease in performance over the day. This explains why after doing physical activities, people feel better and have higher motivation and higher self-confidence. Thereby, American Sleep Disorder Association prescribes physical activity as a key nonmedicinal intervention to deal with sleep disorder. ${ }^{17}$ The results supported the effectiveness of physical activities on improvement of quality of sleep and in turn the improvement of quality of life regarding mental, physical, and social aspects.

\section{Limitations}

The study was not free of limitations; for instance, only males were included in the study, and the role of family members was not taken into account. Future works may examine the effects of physical activities on females.

\section{Conclusion}

Old age is associated with physiological and mental changes, which in some cases create sleep disorders. Our results and those reported by similar works indicated that the majority of the elderly population suffer from sleep disorders. The quality of sleep of the participants can be improved by making them perform organized physical activities. The results supported the effectiveness of the physical activities on the quality of sleep. Adding physical activities to the daily schedule of the elderly is recommended.

\section{Acknowledgments}

This study was taken from a research project approved by Kermanshah University of Medical Sciences (No 92269). The authors express their gratitude to the authorities of Kermanshah Medical Science University, Kermanshah Welfare Org., and Shahid Yari Elderly House who helped in conducting the study.

\section{Disclosure}

The authors report no conflicts of interest in this work.

\section{References}

1. Léger D, Poursain B, Neubauer D, Uchiyama M. An international survey of sleeping problems in the general population. Curr Med Res Opin. 2008;24(1):307-317.
2. Ahmadi S, Khankeh HR, Mohammadi F, Fallahi M, Reza Soltani P. [The effect of sleep restriction treatment on quality of sleep in the elders]. Iran J Ageing. 2010;5(16):7-15. Persian.

3. Kashfi MK, Hani jyhoni A, Farhadi S. [The relationship between socio-demographic factors and the prevalence of depression among the elderly in nursing homes 60 years covered by the welfare Shiraz] Med J Hormozgan. 2011;14(4):319-325. Persian.

4. Mousavi A, Mirzay E, Khosravi A. [Sleep pattern and daytime sleepiness in over-15-year-old people in Shahroud]. Knowledge \& Health. 2010;4(4):45-49. Persian.

5. Haqani H, Asadinooqabi A, Zabolipoor S, Aliasghrpoor M. [The effect of increased blood flow rate during hemodialysis on uremic pruritus induced sleep disorder]. J Knowledge Brought. 2012;17(4):329-336. Persian.

6. Park JH, Yoo MS, Bae SH. Prevalence and predictors of poor sleep quality in Korean older adults. Int J Nurs Pract. 2013;19(2): 116-123.

7. Chia Y, Tung P, Chin L, Chang M. Sleep quality among communitydwelling elderly people and its demographic, mental, and physical correlates. J Chin Med Assoc. 2011;75(2):75-80.

8. Arang I, Manlhiot C, Davies-Shaw J, et al. Sleep disturbance and cardiovascular risk in adolescents. J Can Med Assoc. 2012;184(17): 913-920.

9. Asadnia S, Sepehrianazar F, Mosarrezaii Aghdam A, Saadatmand S. [Comparison of sleep quality and migraine headaches in people with proper and improper and poor sleep]. Urmia Med J. 2013;23(7): 799-806. Persian.

10. Yaremchuk K, Roehrs T. Does perioperative sleep disruption impact pain perception? Laryngoscope. 2012;122(12):2613-2614.

11. Chen M-C, Liu H-E, Huang H-Y, Chiou A-F. The effect of a simple traditional exercise programme (Baduanjin exercise) on sleep quality of older adults: a randomized controlled trial. Int J Nurs Stud. 2012; 49(3):265-273.

12. Marasinghe C. Sleep disorders in elderly. J Ceylon College of Physicians. 2014;43(1-2):37-40.

13. Corman B, Leger D. [Sleep disorders in elderly]. Rev Prat. 2004;54(12): 1281-1285. French.

14. Haimov I, Laudon M, Zisapel N, et al. Sleep disorders and melatonin rhythms in elderly people. BMJ. 1994;309(6948):167.

15. Daneshmandi M, Neiseh F, SadeghiShermeh M, Ebadi A. Effect of eye mask on sleep quality in patients with acute coronary syndrome. J Caring Sci. 2012;1(3):135-143.

16. Driver HS, Taylor SR. Exercise and sleep. Sleep Med Rev. 2000;4(4): 387-402.

17. Reid KJ, Baron KG, Lu B, Naylor E, Wolfe L, Zee PC. Aerobic exercise improves self-reported sleep and quality of life in older adults with insomnia. Sleep Med. 2010;11(9):934-940.

18. Santos RVT, Viana VAR, Boscolo RA, et al. Moderate exercise training modulates cytokine profile and sleep in elderly people. Cytokine. 2012;60(3):731-735.

19. Durcan L, Wilson F, Cunnane G. The effect of exercise on sleep and fatigue in rheumatoid arthritis: a randomized controlled study. J Rheumatol. 2014;41(10):1966-1973.

20. Yang PY, Ho KH, Chen HC, Chien MY. Exercise training improves sleep quality in middle-aged and older adults with sleep problems: a systematic review. J Physiother. 2012;58(3):157-163.

21. Kredlow MA, Capozzoli MC, Hearon BA, Calkins AW, Otto MW. The effects of physical activity on sleep: a meta-analytic review. $J$ Behav Med. 2015;38(3):427-449.

22. Atadokht A, Mohammadi I. Effectiveness of aerobics exercises on sleep quality of chronic psychiatric patients admitted in rehabilitation center in Ardabil. J Rafsanjan Univ Med Sci. 2015;14(1):3-14.

23. Akbari KAA, Shams A, Abdoli B, Shamsipour DP, Mohajeri R. [The effect of low and moderate intensity aerobic exercises on sleep quality in older adults]. SALMAND. 2015;10(1):1-18. Persian.

24. Rohrig B, du Prel JB, Wachtlin D, Kwiecien R, Blettner M. Sample size calculation in clinical trials. Dtsch Arztebl Int. 2010;107:552-556. 
25. Buysse DJ, Reynolds CF, Monk TH, Berman SR, Kupfer DJ. The Pittsburgh Sleep Quality Index: a new instrument for psychiatric practice and research. Psychiatry Res. 1989;28(2):193-213.

26. Li F, Fisher KJ, Harmer P, Irbe D, Tearse RG, Weimer C. Tai chi and self-rated quality of sleep and daytime sleepiness in older adults: a randomized controlled trial. J Am Geriatr Soc. 2004;52(6):892-900.

27. Rahmaninia F, Mohebi H, Gholi SB. The effect of walking on quality, quantity and some physiological parameters related to sleep in old men. SPORT BIOSCIENCES (HARAKAT). 2010;3:111-126.

28. Abbasi B, Kimiagar M, Shirazi M, et al. [Effect of magnesium supplementation on calorie intake and weight loss of overweight or obese insomniac elderly subjects: a double-blind randomized clinical trial]. Iran J Nutr Sci Food Tech. 2012;7(1):31-40. Persian.
29. Ferris LT, Williams JS, Shen CL, Albus KA, Hale KB. Resistance training improves sleep quality in older adults. Med Sci Sports Exerc. 2004;36(5):S287.

30. King AC, Pruitt LA, Woo S, et al. Effects of moderate-intensity exercise on polysomnographic and subjective sleep quality in older adults with mild to moderate sleep complaints. J Gerontol A Biol Sci Med Sci. 2008;63(9):997-1004.

31. Elavsky S, McAuley E. Lack of perceived sleep improvement after 4 month structured exercise programs. Menopause. 2007;14(3):535-540.

32. Rahmaninia F, Mohebi H, Saberian Brojeni M. [Effect of walking on quality, quantity and some physiological parameters related to sleep in old men]. J Sport Bio Sci. 2009;1(3):111-126. Persian.
Clinical Interventions in Aging

\section{Publish your work in this journal}

Clinical Interventions in Aging is an international, peer-reviewed journal focusing on evidence-based reports on the value or lack thereof of treatments intended to prevent or delay the onset of maladaptive correlates of aging in human beings. This journal is indexed on PubMed Central, MedLine,

\section{Dovepress}

CAS, Scopus and the Elsevier Bibliographic databases. The manuscript management system is completely online and includes a very quick and fair peer-review system, which is all easy to use. Visit http://www.dovepress. com/testimonials.php to read real quotes from published authors. 